\title{
On the practical feedback stabilization for evolution equations in Banach spaces
}

\author{
Hanen Damak ${ }^{1}$ \\ ${ }^{1}$ University of Sfax Faculty of Sciences of Sfax
}

November 2, 2020

\begin{abstract}
This paper investigates the notion of practical feedback stabilization of evolution equations satisfying some relaxed conditions in infinite-dimensional Banach spaces. Moreover, sufficient conditions are presented that guarantee practical stabilizability of uncertain systems based on Lyapunov functions. These results are applied to partial differential equations.
\end{abstract}

\section{Hosted file}

DAMAK2020.pdf available at https://authorea.com/users/372225/articles/490337-on-thepractical-feedback-stabilization-for-evolution-equations-in-banach-spaces 